\title{
Digital Ecosystems as a Unit of Scientific Analysis. A Sociological Investigation
}

\author{
Bendik Bygstad \\ University of Oslo \\ Bendikby@ifi.uio.no
}

\author{
Arne Dulsrud \\ Oslo Metropolitan University \\ Arned@oslomet.no
}

\begin{abstract}
The growth of digital ecosystems such as Google, Apple and Uber has led to radical changes in economic activity, work and consumption. It has also challenged established economic, social and organization theory, which has clear limitations in understanding these phenomena. The discourses on these topics are conducted in various arenas, which are not linked, and conceptualise digital ecosystems differently. What kind of theoretical object is this?

The purpose of this study is to present an institutional and comparative analysis of the research on platforms and digital ecosystems. We identify four research streams; political, economic, technological and individual. We analyse each stream regarding the key insights, and identify the most important knowledge sources. Then we assess the relevance of classical and modern sociology for understanding digital ecosystems.
\end{abstract}

\section{Introduction}

"The world's largest taxi firm, Uber, owns no cars. The world's most popular media company, Facebook, creates no content. The world's most valuable retailer, Alibaba, carries no stock. And the world's largest accommodation provider, Airbnb, owns no property. Something interesting is happening.»

Tom Goodwin, Havas Media [1]

Digital ecosystems are changing the world; in business and finance, in production, retail and consumption, in health care and public services, and in dating and love. During the past 20 years few phenomena have caught the interest and fascination as much as the flood of digital platform-based products and services.

How can we conceptualise and theorize these ecosystems from a research point of view? In this study our interest is to investigate digital ecosystems as a unit of scientific analysis. A digital ecosystem is commonly defined as a distributed and adaptive, socio-technical system [2]. Or expressed simpler, a digital ecosystem is a network of people and organisations, connected by digital technology, often with a core, called platform [3]. The terms digital ecosystems, platform ecosystems, or just ecosystems, are often used interchangeably in the literature.

Well-known examples are social media (Facebook, Twitter), mobile networks (Apple, Samsung), supermarkets (Amazon), financial networks such as banks and stock exchanges. Digital ecosystems do not grow though centralised planning, but through network effects [4] and socio-technical mechanisms such as innovation, adoption and scaling [5]. Half of the worlds ten largest companies (in stock value) are platform ecosystems, and billions of people are daily users and customers of these systems.

It is hard to overstate the significance of the global digitalisation wave. Technologically, these companies are structures that the world has never seen before, enabling billions of people to connect to such services as Google and email and Wikipedia. Facebook has two billion users, but response time is shorter than your local Intranet. Economically, it means that the hegemony has moved from pipeline companies (traditional value chain firms) to platform companies, such as Amazon and Uber [6]. It means that established theories on economies of scale and scarce resources are supplanted by theories of multisided markets and network effects. Politically, the social media has led to a dramatic change in the public discourse, with new possibilities for participation, but also manipulation. Culturally, it includes a fast globalization of media and communication forms, where the New York stockbroker and the fisherman in Sri Lanka live in the same digital world.

What does it mean in sociology and organization theory? Digital ecosystem is a metaphor from biology, 
and may be somewhat misleading in the sense that the mechanisms and dynamics of biological ecosystems are quite different from the socio-technical structures we study here [2]. However, the term is widely used both in research and practice, and we approach it as an empirical and theoretical concept. Recently, De Reuver et al. argued that the object of study lacks conceptual clarity, and asked for definitions that specify the unit of analysis, degree of digitality and the sociotechnical nature of digital platforms [7].

At the same time, there is a growing recognition that digitalization in general has had little impact on the sociological discipline itself or on the research practices [8]. According to Daniels et al [9], sociology has been "less concerned with redefining itself through the understanding of the digital", and it was not until 2013 that the first book with the title "digital sociology" appeared [10]. In our view, digitalisation represents a profound change on how we organize society, socialize, interact and the way we access goods and services, and sociology needs to offer a compelling and theoretical understanding of the current shifts caused by digital technologies [11][12]. Digitalization, in other words, represents a sweeping opportunity for understanding of social change and for framing societal challenges in general. Conceptually and analytically, we regard digital ecosystems an entry-point for understanding the social dynamics of the new technology.

How can sociological theory contribute to our understanding of digital ecosystems as a unit of empirical and theoretical analysis? We conduct our investigation by identifying four streams of research, and analyse the relevance of sociological theory for each stream and each contribution.

A key sociological contribution relevant for our work is institutional theory [13]. Institutions are the stable social forms and patterns, and the establishment and use of power. Institutions consist of regulative, normative and cultural-cognitive elements that, together with associated activities and resources, provide stability and meaning to social life. An early sociological contribution to the institutional analysis of networks was Granovetter's work [14] on social networks.

Our research questions are therefore, what can digital ecosystem research learn from sociology? And what can sociology learn from digital ecosystem research?

\section{Method}

By crossing disciplinary boundaries, our major objective is to identify and relate literature of digital ecosystems to contributions in sociology. According to Webster and Watson [15], there are several concerns of assembling a review in an interdisciplinary field because we often need to draw on theories from a variety of fields. Furthermore, as the topic of digital ecosystems is an emergent topic, the author's contribution would arise from identifying the fresh theoretical foundations and in elaborating a concepts rather than presenting as thorough synthesis. The review of current literature on the emerging topic would, according to Webster and Watson, of necessity, be shorter.

Since the amount of emerging current research is overwhelming, we applied a rapid research [6] and snowball method in combination, in order to get an overview of the literature. The review was organized into four steps. We first made an open search on Google Scholar, Scopus, Proquest, and Web of Science in order to get a general idea of the scope of literature. As an emerging field of research, the concept "digital ecosystem" is characterized by an immense volume of scholarly attention from a broad range of academic fields (about 13.900 matches on Google Scholar). In the second step, we restricted the selection of units by using queries that were expected to capture the institutional attributes of digital ecosystems. We applied hyphenated keywords, such as "platform ecosystem", "platform capitalism", "digital governance" "peer-to-peer platforms", "internet monopolies" etc. The number of matches were limited to between 100 and 2000. During the third step, through Google Scholar, we chose a selection of 30-40 titles with the highest number of citation scores. The snowball method were used to assemble and to identify units that we interpreted as major contributions. Exclusion criteria were deployed; we selected only studies of platform ecosystems, i.e. n-sided markets or structures, excluding other digitalization phenomena, such as GDPR, internet of things (IoT) and artificial intelligence.

In the final stage, we employed an iterative process of inductive classification. The process ended in the following classification of four streams according to their keywords :

- $\quad$ Market stream; platform economics, data driven economy, network externalities, two-sided markets

- Technological stream; platform ecosystems, peer-to peer platforms, online platforms, platform tuning

- Political stream; information capitalism, surveillance capitalism, Internet monopolies

- Social and cultural stream; sharing economy, op-in consent, self-tracking, 
opt-out consent, data privacy, consumer rights and big data.

We conducted further data analysis by assessing each contribution by the following questions: how is digital ecosystem conceptualised; what is the research question and what is the major hypothesis. We used these distinctions to identify sub-streams. Then we applied the institutional perspective, assessing how the research object was defined, and what characterised the institutional logic, in terms of social construction, practices, justification, values and power relations. In spite of its advantages, the rapid research has obvious challenges related to sampling and choosing biases, of which is further discussed under section 4.3.

\section{Literature Review: Four Streams}

Online markets, such as eBay, were introduced in the 1990s. The first occurrence of the metaphor "digital ecosystem" is often attributed to an EU Commission publication [2], which addressed how digital technology should overcome the fragmented markets of Europe. A few years later, the term "platform ecosystems" were used to describe the digital ecosystems of Apple and Android, as the device companies BlackBerry and Nokia lost the competition against the platform firms [16].

A recent literature review on platform ecosystems was conducted by Schreieck et al. [17]. They identified two streams, one focusing on technology and one focusing on markets and economics. Further, they investigated which perspectives the studies were built on, and found that most of them were conducted from the viewpoint of the platform owner. Fewer were conducted from the vendor perspective, and even fewer (10 of 61) from the user perspective.

Based on our literature analysis we offer a somewhat more finely granulated typology, illustrated in Table 1.

\subsection{Market stream}

The market stream is primarily built on the theory of network externalities. A network externality is here that, invisible for the individual actors, the value of the network grows much faster than the growth of users. Theories on network effects and n-sided market dynamics were developed by researchers such as Katz and Shapiro [21] and Rochet and Tirole [22]. A strategy perspective, defining platform ecosystems as the world's innovation engine, was later proposed by Parker and Van Alstyne [23]. These contributions set digital ecosystems in the center of current economic and strategy theory. The underlying research question is, how does platform ecosystems deal with market imperfections?

Table 1. Research streams

\begin{tabular}{|l|l|l|}
\hline Stream & Focus & $\begin{array}{l}\text { Key contri- } \\
\text { butions }\end{array}$ \\
\hline $\begin{array}{l}\text { 1.Market } \\
\text { stream }\end{array}$ & $\begin{array}{l}\text { Network externalities } \\
\text { n-sided markets, }\end{array}$ & $\begin{array}{l}\text { Parker et al., } \\
\text { 2016 [18] }\end{array}$ \\
\hline $\begin{array}{l}\text { 2. Techno- } \\
\text { logical } \\
\text { stream }\end{array}$ & $\begin{array}{l}\text { Ecosystem } \\
\text { architecture and } \\
\text { governance }\end{array}$ & $\begin{array}{l}\text { Tiwana, } \\
2014[19]\end{array}$ \\
\hline $\begin{array}{l}\text { 3 Political } \\
\text { stream }\end{array}$ & $\begin{array}{l}\text { Surveillance } \\
\text { capitalism, internet } \\
\text { monopolies }\end{array}$ & $\begin{array}{l}\text { Zuboff, 2018 } \\
{[20]}\end{array}$ \\
\hline $\begin{array}{l}\text { 4. Social } \\
\text { and } \\
\text { cultural } \\
\text { stream }\end{array}$ & $\begin{array}{l}\text { Consumer, sharing } \\
\text { economy, opt-in } \\
\text { consent, self- } \\
\text { tracking, data } \\
\text { privacy, }\end{array}$ & $\begin{array}{l}\text { Lupton 2016 } \\
{[8]}\end{array}$ \\
\hline
\end{tabular}

From a more practical business perspective Gawer and Cusomano [24] addressed competitive strategies, and Clemons [25] discussed the options for sustainable competitive advantage in platform ecosystems. Several studies were conducted on mobile phone ecosystems, such as Ondrus et al. [26] study on the impact of openness on the market potential of multisided platforms, and Eaton et al.'s investigation on platform tuning [27].

From a sociological perspective these contributions are concerned with platform ecosystems as economic institutions, i.e. organised efforts to deal with market imperfections. From this perspective a platform is an institution that effectively links sellers and buyers, like a medieval market connects farmers and city dwellers. A digital platform works much the same way, but is connected to a much larger ecosystem, through digital technology. Parker et al. (2015) [18] argued that a platform company, as an organisational form, is vastly superior in competitive terms, compared to a "pipeline" company: in open competition Uber will win over local taxi firms, and Airbnb will win over local room vendors. The simple reason is that transaction costs (both information, contract and payment costs) are much lower.

Some contributions discussed the institutional logic of platform ecosystems, focusing on the practices of platform owners and the interplay with platform users. For instance, Gawer and Cusomano [24] and investigated how platform companies such as Microsoft create their environments, but also their threats, because the power relations between platform owners and platform users is unstable and under continuous negotiation. In the same vein, Eaton [27] 
showed, with the Apple ecosystem as example, that platform ecosystems experience conflicts between control and autonomy. This is mitigated by tuning, i.e. a dialectic process of resistance and accommodation, where actors with different positions and interests in the ecosystem continually reshape the ecosystem logic through micro-actions.

The market stream has mainly focused on market efficiency, and to a lesser degree addressed the more problematic aspects of the market dominance of such actors as Google, Amazon and Airbnb. There are some exceptions to this. The Nobel Prize Winner Tirole recently warned against the increasing tendency to natural monopoly situations, and a winner-take-all scenario [28].

\subsection{Technological Stream}

The technological stream deals with the development of large socio-technical networks, but also with various technical architectures for digital ecosystems. One foundational contribution is Hughes' [29] work on the development of the American power grid as a technical and political process. Hanseth and Monteiro [30] introduced the concept of information infrastructure, moving from single IT systems to connected infrastructures. Building on actor-network theory they showed how such infrastructures grow organically through use, not planned design.

The basic technical structure of platform ecosystems was described by Baldwin and Woodard [3]; platform ecosystems are composed by a stable core, and external components with great variety. To this Ghazavneh and Henfridsson ([31] added that the platform owner connects and governs the ecosystem through boundary resources. The underlying research question is, how does platform ecosystems mitigate technical complexity?

A central contribution is Tiwana's "Platform Ecosystems" [19], describing the technical structure in typical platforms such as Airbnb and Uber. Two aspects are central; architecture and governance. Architecture concerns the structure of digital ecosystems, while governance primarily deals with the relationship between platform owner, vendors and users. O'Reilly [32] showed that also the public sector is well suited for platform thinking, since public registers can become platforms for public services.

From a sociological perspective these contributions are concerned with platforms as technical institutions, i.e. organised efforts to deal with technical complexity. The organisational logic of technical ecosystems has been addressed in various ways. While Tiwana [19] was concerned with the architecture and governance of the simple and ideal- typic platforms of Uber and Airbnb, other researchers have investigated more complex structures [33]. Another example from the growing field of programmatic advertisement is Alaimo and Kallinikos' study [34] of how ecosystems transfer power from the publisher companies to the advertising firms and their algorithms.

The technical power of platform ecosystems originates from two characteristics; (i) they introduce a specific order of platform core, boundary resources, and complements (such as apps) and (ii) they balance the forces of centralization and autonomy through governance mechanisms.

Governance aspects have been discussed mainly from the perspective of the platform owner [19], but some researchers, such as Wareham et al., have proposed various forms of more distributed governance to mitigate the tensions between different actors [33].

\subsection{Political Stream}

The political stream can be linked to the study of the connection between technology and societal formation, particularly related to concepts as power, institutionalization, governance and organization. We identify two sub-streams; a future optimistic approach strongly influenced by sociological modernization theory and a more critical research stream inspired by neo-marxist theories from the 1960's and 70's, such as Braverman.

The first sub-stream emphasizes great paradigmatic shifts of society as a result of technological progress, particularly related to information technology and data processing. In his book The coming of the post-industrial society Daniel Bell [35] outlined how the industrial society was superseded by the post-industrial society, that was mostly information-led and service-oriented. Although neither the Internet nor digital platforms existed when Bell wrote his book, Bell predicted how access to huge quantities of data, and techniques of processing and data analysis would be a crucial component in the transformation to a post-industrial. In his book The Third Wave [36], Alvin Toffler was more explicit on the role of how information technology reorganizes our everyday life and reconfigures organizational structures in terms of social integration and non-hierarchical structures. Although being accused of being utopian in his depiction of future societies, several of his concepts have become adopted as analytical concepts, He argues that technological development leads to a reintegration of production and consumption coined as "the rise of the prosumer", a concept that later was 
reintroduced by Ritzer [37] as a criticism of marxism and post-modernist theories. In a similar vein, Klaus Schwab - founder and chairman of World Economic Forum - envisaged nothing less than a "transformation of humankind" in his book The Fourth Industrial Revolution [38]. Due to technological breakthroughs, such as artificial intelligence, new digital infrastructures and the Internet of things, we are “.... at the beginning of a revolution that is fundamentally changing the way we live, work, and relate to one another". Schwab's narrative has had a massive impact on the way visionary businesspersons and politicians express themselves, communicate and interpret the future in positive and optimistic terms. Evgeny Morozev (2013:168) observed that the historiography of technology has a tendency of "proinnovation bias" in the sense that articles on innovations tend to avoid the negative and undesirable outcomes of innovation [39]. Such "pro-innovation bias", Morozev contends, is responsible for the belief that all innovations are benevolent to society whereas innovations in for example the pharmaceutical industry reveals that there are reasons to examine issues such as justice in the diffusion of innovation. "This requires going beyond preoccupation with novelty and efficiency and asking difficult, normative questions about power, legitimacy, and morality" (2013:169).

The second sub-stream, with less public attention, gather inspiration from critical theories of the post-war period. From a Marxist point of view, technology was regarded as a factor that could mitigate the antagonism between work and capital, particularly when it came to explaining why capitalism prevailed as a social and economic system, in spite of the prophecies of Karl Marx. According to Srnicek in his book Platform Capitalism [40], technological startups and digital platforms became a valuable and attractive target for venture capital investments in the 1990's, when the profit-rate in conventional industries plunged. As such, digital platforms and digital ecosystems created the engine that could reform modern capitalism - creating a new dynamic of economic growth.

Shabana Zuboff [41] was even more explicit in demonstrating how digital ecosystems and big data relates to political economy, using the Google ecosystem as her empirical evidence. In her seminal article Big other: surveillance capitalism and the prospects of an information civilization, she described and analyzed the emergence of «surveillance capitalism" and how Google's exploitation of personal data is intrinsically tied to a new form of "accumulation logic" within modern economies. Furthermore, she argues that algorithms aimed at predict social behavior contributes to new structures of power, which leads to alienation and commodification of peoples' everyday life.

Bauman and Lyon [42] have voiced a similar critique. Modern surveillance techniques described as liquid are neither mundane nor delimited, but a technique that penetrates all activities of everyday life. While surveillance exists in a "global and exterritorial space», power is "planetary". Modern surveillance techniques detache the connection between politics and power and challenges modern democracy.

Through an in-depth and detailed analysis of high-frequency trading algorithms operating among buyers and sellers of shares, Donald Mackenzie [43] demonstrated that the very configuration of these algorithms are socially embedded. The procedures envisaged by the algorithms are contingent products of their interaction with people, organizations, machines, patterns of trading and a "result of conflicts with strong meso-level political economy impacts" (p.1677). McKenzie challenges Tiwana's sharp distinction between governance and architecture by claiming that algorithms are not technologically inherent or disentangled from social life.

\subsection{Social and Cultural Stream}

The social and cultural stream covers the relationship between the social actor and the digital ecosystem. There is a large body of literature that focuses on the social micro-level, more specifically on the relationship between the acting individual and the digital ecosystem. For this research stream, there are two overarching research questions - how does digital ecosystems affect social interaction, and to what extent does patterns of social interaction affect the design of digital solutions. From a sociological perspective, we find a spectrum of theoretical approaches, ranging from technology-deterministic approach on the one end, to a social-constructivist on the other where different variations over socialtechnical and practice-oriented theories are to be found as middle-positions. Whereas the two first positions are assuming a one-way causal index, the middle positions rely on a mutual causal relationship between social interaction and digitalization. These theoretical positions will be further explored below.

Thematically, we will divide the individual research stream into three major topics: sharing, surveillance and risk and consumer rights. The concept of sharing on-line has strong theoretical connotations in the social sciences both as mode of social interaction and as a mode of economic exchange [44]. Both elements are present in the current notion of sharing economy which has become a description 
on how digital platforms and ecosystems enables the emergence of new market and non-market mechanisms for the allocation of goods and services (cooperatives, recycling arrangements etc). The latter include peer-to-peer platforms where monetary compensations either are absent or does not constitute the reference of value for the allocations of goods, services and labour [45] (p.128). Classical examples are Wikipedia or open access programs used by Linux or GNU.

The concept of sharing economy remains contested as a description on the functioning of digital exchange mechanisms [46]. The term is rhetorically used with businesses such as Airbnb, Uber and Deliveroo, with 'alternative' economic initiatives including car sharing apps, community energy cooperatives, and alternative currencies. Their business model and approaches to the economy vary. These differences frequently collide in disagreements, antagonisms and attempts to influence change from civil society and business, with protests, blockades, petitions, lobbying and controversial public policy strategies. Humphreys and Grayson [47] argues that sharing economy only represents a transfer of tasks that is often unpaid from the supplier to the consumer. Constantinou and Kallinikos argue that goods and services are paid by the transfer of personal data used for commercial purposes, «In such contexts, socialplatform users become producers of information and consumers of services based on the information they themselves produce, as shown by recommender systems and personalization services» [48].

There is a growing literature exploring the ways in which people use digital platforms to monitor, evaluate and optimize themselves through technologies of self-tracking. Lupton [8] argues that various forms of intended and non-intended digitized self-tracking is a form of "dataveillance," that can be associated with the emergence of what she denotes as "the quantified self". Lupton contends that these technologies raise new issues on the use of people's personal information about their lives and bodies. Ultimately, dataveillance have "implications for concepts of selfhood and citizenship" [8]. Although aspiring at placing self-tracking as a social phenomenon within a broader socio-cultural context in terms of "biocapital and data politics", Lupton's analysis remains relatively micro oriented at the individual level.".

Daniel Miller et al [49] offer a less deterministic and a more voluntarist approach to how social media and digital platforms interact with people's life. In their study conducted among users of social media in 8 countries they conclude that users shape social media and not the other way around:
"Platforms and their properties are less important as their cause of content" (p.ix). They oppose the premise that activities on social media lead to individualism or shallow relationship; instead they complement social networks by bridging the distinction between private and public life. Miller's findings oppose the conventional portrayal of the digital platform user as a vulnerable victim of platforms owners that are exploited both in terms of being a supplier of valuable privacy data and as a customer of products and services

\section{Discussion}

In this section we assess our findings. Our basic claim is that the literature on digital ecosystems is rapidly expanding yet fragmented. This is because the field of digital ecosystems (i) is multi-disciplinary, (ii) there is a variety of contexts in which digital ecosystems are conceptualized and defined, and (iii) platforms operate across many different sectors and social domains; all of which means that there are numerous economic, political, social and cultural impacts. We argue that both the study of digital ecosystems and the field of sociology will benefit from cross-fertilization, by identifying research gaps and potential focuses of research.

\subsection{What can digital ecosystem research learn from sociology?}

The four research streams all have important contributions, and, as shown in our review of them, they do not, with a few exceptions, draw much on sociological theory. In this section we discuss how sociological insights on empowerment can enrich the digital ecosystem research. An overview of our argument is shown in Table 2.

The market stream focuses mainly on economic efficiency. Recently, however, a public debate has risen on the issue of monopolistic power of the large Internet companies, and the European Union has initiated regulation in various forms. From an academic point of view Tirole [28] has called for a reassessment of the role of these giants.

Power is a key sociological concept. In his work on legitimate power Max Weber [50] analysed in detail the development of two interacting systems; market capitalism and government regulation. For Weber the modern state represented the legal and institutional underpinnings of the capitalist economy, although this may not be visible to the individual entrepreneur.

As we have been reminded of by Mazzucati (2013) the basic Internet technologies were in fact developed 
by government-financed institutions, such as defence agencies and universities [51]. Thus, the established image of frictionless capitalism, as championed by many researchers in the economic stream, should at least be supplemented by a sociologically informed analysis of the role of government, and of the power relations in the digital economy. In particular, the asymmetrical relationships between the Internet giants and the individual customer should be analysed in an institutional context, not only in terms of economic transactions.

At the macro level, there should be room for research combing the institutional insights from sociology and digital ecosystems to explore further the state versus market relationship, as envisioned by the proponents of critical theory. As Srnicek [40] observed, technology develops so rapidly, that path dependency and market institutions have been settled before corporate regulation can enter into force. Karl Marx described how colonial trading companies developed and operated both beyond and in tandem with national jurisdiction and political regulation. Similarly, The Economist (History's biggest firms, The Economist 5.07.2018) compared the revenues of digital platform such as Amazon and Apple to the monopolistic infrastructures of trade such as the East India Company that was transnational by nature, and emerged outside the scope of national law enforcement. There is certainly a challenge in conceptualizing and framing theoretically the societal impacts from the global digital ecosystems.

Table 2 Limitations and contributions

\begin{tabular}{|l|l|l|}
\hline Stream & $\begin{array}{l}\text { Limitations in } \\
\text { research }\end{array}$ & $\begin{array}{l}\text { Possible } \\
\text { sociological } \\
\text { contribution }\end{array}$ \\
\hline $\begin{array}{l}\text { 1.Market } \\
\text { stream }\end{array}$ & $\begin{array}{l}\text { Market } \\
\text { efficiency bias }\end{array}$ & $\begin{array}{l}\text { Power and } \\
\text { monopolies }\end{array}$ \\
\hline $\begin{array}{l}\text { 2. Techno- } \\
\text { logical } \\
\text { stream }\end{array}$ & $\begin{array}{l}\text { Technical } \\
\text { efficiency bias }\end{array}$ & $\begin{array}{l}\text { Alternative } \\
\text { governance } \\
\text { models }\end{array}$ \\
\hline $\begin{array}{l}\text { 3 Political } \\
\text { stream }\end{array}$ & $\begin{array}{l}\text { Biased on } \\
\text { technological } \\
\text { and societal } \\
\text { progress }\end{array}$ & Critical theory \\
\hline $\begin{array}{l}\text { 4. Social } \\
\text { and cultural } \\
\text { stream }\end{array}$ & $\begin{array}{l}\text { Individualistic } \\
\text { bias }\end{array}$ & Structural theory \\
\hline
\end{tabular}

The technical stream mainly focuses on the technical structures, dealing with platform cores, apps and boundary resources [31]. The governance models deal typically with the relationships between platform owner on the one side, and the vendors and customer on the other [19].

It is clear that digital ecosystems, transcending organisational borders, challenges traditional corporate governance. One important sociological discourse addresses alternative governance models. The Nobel Prize winner Elinor Ostrom [52] investigated shared resource management, and has inspired new approaches in polycentric governance. This entails a governance structure where many decision centres work independently, but constructively. The key to this ideal situation is a set of shared rules.

In understanding how digital ecosystems evolve, MacKenzie [43] offered an epistemological critique of the division between governance and algorithms. Because algorithms themselves are socially embedded, he recommends an integration of actornetwork theory and economic sociology that are sensitive "to conflict and to matters of political economy, structural advantage, the law, and government" (p.1678). It remains to be seen, however, whether the findings of MacKenzie can be used to analyse distributional effects, justice and injustice, and power in theoretical terms.

There are good examples of such systems in the digital field, such as Wikipedia and open-source software. While there are some contributions on polycentric governance in the technical stream literature [53] the impact is limited. We believe that there is a great potential in developing this field further. In particular, the practical and empirical research in the technical stream should extend its interest to new forms of governance.

The political stream focuses on the interaction between digital infrastructures and the paradigmatic shifts of societal macro structures in term of political, economic and social institutions. The idea of a Fourth Industrial Revolution [38] remains as a prominent example. Recent literature has disputed the tendency in the literature to what Morozov [39] denotes as the pro-innovation bias, which considers all new technology as successful, progressive and risk-free.

It is clear, as the disputes around Apple, Google and Facebook has exhibited, that the digital ecosystems have challenged corporate regulation, consumer protection, public control over urban infrastructure, competition policy, workers' rights, taxation regimes and the intersection between market and state at the very overarching level. Paradoxically, we observe a revival of critical theory with roots in theories of classical political economy from the $19^{\text {th }}$ century (Emile Durkheim, Karl Marx, Max Weber), led by scholars from various fields of expertise, with Shoshana Zuboff as a prominent example. Sociology 
has been relatively absent in this discourse, and we assume that there is a great potential of advancing this field further in terms of a more comprehensive theoretical framework, which emphasise strategic action and the continuous character of struggles among multiple collective actors.

The social and cultural stream focuses on the relationship between digital ecosystems and social interaction enabled by digital platforms. The emerging body of literature emphasizes the challenges and risks of the individual user associated with the sharing economy, social media and technologies of selftracking for the individual.

There are shortcomings in this literature that could be compensated by through a more comprehensive and comparative institutional approach. Deborah Lupton's [8] analytical approach to self-tracking leaves no space for integrating institutional patterns of governance and organisational structures. Subsequently, her conclusions are relatively vague when it comes to social and individual consequences. On the one hand, self-tracking data can be mobilized as an institutional audit culture that can be used to control others, on the other hand self-tracking can be used for "resistant or strategic political interventions. Daniel Miller et al's [49] refreshing study of social media users contest the inherent victimisation of the digital platform user in conventional theory, and calls for research that are more comparative by nature and that engage with digital platforms from the perspective of its users.

\subsection{What can sociology learn from digital ecosystem research?}

The four streams on digital ecosystems provide a number of important insights relevant for sociological research, both at a micro and macro levels. Our key point here is that although digital ecosystems are experienced at a personal and group level, we need to study the phenomenon also from a macro level. One prominent example is Castell's trilogy from the 1990s [11], which was empirically strong, but with limited theoretical impact.

After Castell's work sociological macro studies of the digital economy are scarce. An exception is Srnicek's [40] book on platform capitalism, which although not being a strictly sociological study contributed a detailed analysis of the power relations in the platform economy. Srnicek discussed in particular the key resource of raw data, exemplified by Google's use of personal data to sell ads, and the unprecedented accumulation of capital in the platform firms. From our point of view, a salient aspect of his work is that he integrates the analysis of platform ecosystems into a broader societal discourse.
One way forward for sociology research could be to renew the social network tradition from Granovetter [14], by expanding the object of study from social to large socio-digital networks. One interesting inspiration - again, not sociological - is Barabasi's (2006) [54] book on networks, where he discussed the power of networks at many levels; physics, biology, technology and sociology.

In Digital Sociology: The Reinvention of Social Research Nortje Marres [55] called for interdisciplinary studies of the digital, and challenged the discipline: "Indeed, the digital is today opening up a new 'crisis of representation' as it casts doubt on the capacity of social research to adequately and legitimately represent society" (p.14) .

Elaborating on this she discussed the object of study; are sociologists investigating the social or the digital? She found that the answer is not obvious, as the object of digital social enquiry is ambiguous. Both technology and social structures and practices inflict digital formations, and it may be difficult to entangle them. Earlier research in actor-network theory [56] proposed that the borders between the technical and the social are useful for differentiating academic disciplines, but is not a demarcation that reflects the experienced world. A sophisticated, but perhaps not very clarifying discourse on these issues has been conducted the past few years in the Information Systems research on socio-materiality [57].

We conclude this section by calling for interdisciplinary studies. The digital ecosystems that change the world economy and societies at rapid speed call for many types of studies. One particularly interesting way forward would be larger projects for developing new theory, in the intersection of economics, computer science, information systems and sociology.

\subsection{Limitations}

The benefit of rapid research is that it is good for new and emerging research topics without fixed disciplinary boundaries in order to provide an overview [6]. There are also disadvantages, such as sampling bias, choosing bias and obtaining accurate data bias. In a field of indefinable disciplinary boundaries, sampling bias is a factor that has to be taken into account. There is a risk that keywords operate differently across disciplines in terms of exclusion and inclusion criteria, particularly towards social science in the sense that technological terms are less inclined to include relevant social science literature. The snowball method was used to compensate. A preliminary draft of this paper was presented at the interim conference of the European 
Sociological Association 2019 in order to detect both sampling and choosing bias.

\section{Conclusion}

From a sociological point of view, we have assessed the research of digital ecosystems. We find that these streams provide a number of exciting insights, which indeed should be addressed by sociology researchers. We also identify two limitations. First, the different discourses are not connected, leading to separate silos of knowledge. Second, we attribute this problem to the fact that the object of study is defined too narrowly.

We propose that sociological theory and imagination can mitigate these weaknesses. In particular, we argue that, in dealing with the Internet giants, sociological empowerment theory, can contribute to a deeper understanding. On a macro level an analysis of power relations can reveal structural patterns, on a meso level we can leverage alternative governance models, and on a micro level we can renew network research.

\section{References}

[1] Goodwin, T., "The Battle Is For The Customer Interface," 2019. [Online]. Available: https://techcrunch.com/2015/03/03/in-the-age-ofdisintermediation-the-battle-is-all-for-the-customerinterface/?guccounter $=1$.

[2] Nachira, A., Nachira, F., and Dini, P., Digital Business Systems. EU Publications, KK-76-06-475-EN-C, 2007.

[3] C. Baldwin and C. J. Woodard, The Architecture of Platforms: A Unified View. 2008.

[4] S. K. Parker, "Longitudinal effects of lean production on employee outcomes and the mediating role of work characteristics," Journal of Applied Psychology, vol. 88, no. 4, pp. 620-634, 2003.

[5] O. Henfridsson and B. Bygstad, "The Generative Mechanisms of Digital Infrastructure Evolution," MIS Quarterly, vol. 37, no. 3, pp. 907-931, 2013.

[6] J. Harker and J. Kleijnen, "What is a rapid review? A methodological exploration of rapid reviews in Health Technology Assessments," International Journal of Evidence-Based Healthcare, vol. 10, no. 4, pp. 397-410, 2012.

[7] G. A. de Reuver, C. Sørensen, and R. C. Basole, "The digital platform: a research agenda," Journal of Information Technology, p. urn:issn:0268-3962, 2017.

[8] D. Lupton, "The diverse domains of quantified selves: self-tracking modes and dataveillance," Economy and Society, vol. 45, no. 1, pp. 101-122, 2016.
[9] J. Daniels, K. Gregory, and T. M. Cottom, Digital sociologies. Bristol, UK: Policy Press, 2017.

[10] K. Orton-Johnson and N. Prior, Digital sociology : critical perspectives. Basingstoke: Palgrave Macmillan, 2013.

[11] M. Castells, "Toward a Sociology of the Network Society," Contemporary Sociology, vol. 29, no. 5, pp. 693699, 2000.

[12] S. Sassen, "A Sociology of Globalization," Analisis Politico, vol. 20, no. 61, 2007.

[13] W. R. Scott, Organizations: Rational, Natural, and Open Systems. Englewood Cliffs NJ: Prentice Hall Inc., 1981.

[14] M. Granovetter, "Economic Action and Social Structure: The Problem of Embeddedness," American Journal of Sociology, vol. 91, no. 3, pp. 481-510, 1985.

[15] J. Webster and R. Watson, "Analyzing the past to prepare for the future: Writing a literature review," MIS Quarterly, vol. 26, no. 2, pp. xiii-xxiii, Jun. 2002.

[16] A. Tiwana, Konsynski, B, and Bush, B., "Research Commentary \&mdash," Information Systems Research, vol. 21, no. 4, pp. 675-687, 2010.

[17] M. Schreieck, M. Wiesche, and H. Krcmar, Design and Governance of Platform Ecosystems - Key Concepts and Issues for Future Research. 2016.

[18] G. G. Parker, M. Van Alstyne, and P. C. Choudary, "Pipelines, Platforms, and the New Rules of Strategy," Harvard Business Review, vol. April, 2016.

[19] A. Tiwana, Platform Ecosystems. Morgan Kaufmann Publisher, 2014.

[20] S. Zuboff, The age of surveillance capitalism : the fight for a human future at the new frontier of power, First edition. New York: PublicAffairs, 2018.

[21] M. L. Katz and C. Shapiro, "Systems Competition and Network Effects," Journal of Economic Perspectives, vol. 8, no. 2, pp. 93-115, 1994.

[22] J.-C. Rochet and J. Tirole, "Platform Competition in Two-Sided Markets," Journal of the European Economic Association, vol. 1, no. 4, pp. 990-1029, 2003.

[23] G. G. Parker, M. Van Alstyne, and P. C. Choudary, Platform Revolution: How Networked Markets Are Transforming the Economy And How to Make Them Work for You. W. W. Norton \& Company, 2016.

[24] A. Gawer, Platform leadership : how Intel, Microsoft, and Cisco drive industry innovation. Boston, Mass: Harvard Business School Press, 2002.

[25] E. K. Clemons, "Resources, Platforms, and Sustainable Competitive Advantage: How to Win and Keep on Winning," in New Patterns of Power and Profit: A

Strategist's Guide to Competitive Advantage in the Age of Digital Transformation, E. K. Clemons, Ed. Cham: Springer International Publishing, 2019, pp. 93-104. 
[26] J. Ondrus, A. Gannamaneni, and K. Lyytinen, "The impact of openness on the market potential of multi-sided platforms: a case study of mobile payment platforms," Journal of Information Technology, vol. 30, no. 3, pp. 260 275, Sep. 2015.

[27] B. Eaton, S. Elaluf-Calderwood, C. Sørensen, and Y. Yoo, "Distributed Tuning of Boundary Resources: The Case of Apple's iOS Service System," MIS Quarterly, vol. 39, no. 1, pp. 2017-243, 2015.

[28] J. Tirole, Economics for the common good. Princeton: Princeton University Press, 2017.

[29] T. P. Hughes, Networks of power : electrification in western society, 1880-1930. Baltimore: Johns Hopkins University Press, 1983.

[30] O. Hanseth and E. Monteiro, "Inscribing Behaviour in Information Infrastructure Standards," Accounting, Management and Information Systems, vol. 7:4, pp. 183211, 1996.

[31] A. Ghazawneh and O. Henfridsson, "Balancing Platform Control and External Contribution in Third Party Development: The Boundary Resources Model," Information Systems Journal, vol. 23, no. 2, pp. 173-192, 2013.

[32] T. O'Reilly, “Government as a Platform," Innovations: Technology, Governance, Globalization, vol. 6, no. 1, pp. 13-40, 2011.

[33] Wareham, J, Fox, P.B., and Giner, C., "Technology Ecosystem Governance," Organization Science, vol. 25, no. 4, pp. 1195-1215, 2014.

[34] C. Alaimo and J. Kallinikos, "Objects, metrics and practices: An inquiry into the programmatic advertising ecosystem," IFIP Advances in Information and Communication Technology, vol. 543, pp. 110-123, 2018.

[35] D. Bell, The coming of post-industrial society : a venture in social forecasting. New York: Basic Books, 1973.

[36] A. Toffler, The third wave. New York: William Morrow, 1980.

[37] G. Ritzer and N. Jurgenson, "Production, Consumption, Prosumption: The nature of capitalism in the age of the digital 'prosumer,"' Journal of Consumer Culture, vol. 10, no. 1, pp. 13-36, 2010.

[38] K. Schwab, The fourth industrial revolution. Genève: World Economic Forum, 2016.

[39] Morozov, E., "To Save Everything, Click Here: The Folly of Technological Solutionism.(NEW IN PAPERBACK: Highlights of this season's releases)," Nature, vol. 508, no. 7495, p. 183, 2014.

[40] N. Srnicek, "The challenges of platform capitalism: Understanding the logic of a new business model," Juncture, vol. 23, no. 4, pp. 254-257, 2017.

[41] S. Zuboff, "Big other: surveillance capitalism and the prospects of an information civilization," Journal of
Information Technology, vol. 30, pp. 75-89, 2015.

[42] Z. Bauman, Liquid surveillance : a conversation. Cambridge: Polity, 2013.

[43] D. Mackenzie, "Material Signals: A Historical Sociology of High-Frequency Trading 1," American Journal of Sociology, vol. 123, no. 6, pp. 1635-1683, 2018.

[44] R. Belk, "You are what you can access: Sharing and collaborative consumption online," Journal of Business Research, 2013.

[45] P. Mason, PostCapitalism : a guide to our future. London: Penguin Books, 2016.

[46] K. Frenken and J. Schor, "Putting the sharing economy into perspective," Environmental Innovation and Societal Transitions, vol. 23, no. C, pp. 3-10, 2017.

[47] A. Humphreys and K. Grayson, The Intersecting Roles of Consumer and Producer: A Critical Perspective on CoProduction, Co-Creation and Prosumption, vol. 2. 2008.

[48] I. D. Constantiou, "New games, new rules: big data and the changing context of strategy," Journal of Information Technology, vol. 30, no. 1, pp. 44-57, 2015.

[49] D. Miller et al., How the World Changed Social Media. UCL Press, 2016.

[50] M. Weber, "Economy and Society: An Outline of Interpretive Sociology," in Economy and Society: An Outline of Interpretive Sociology, G. Roth and C. Wittich, Eds. Berkeley: University of California Press, 1978.

[51] M. Mazzucato, The entrepreneurial state : debunking public vs. private sector myths. New York: PublicAffairs, 2015.

[52] E. Ostrom, Governing the commons : the evolution of institutions for collective action. Cambridge England: Cambridge University Press, 1990.

[53] Constantinides, P. and Barrett, M., "Information Infrastructure Development and Governance as Collective Action," Information Systems Research, vol. 26, no. 1, pp. 40-56, 2014.

[54] A.-L. Barabási, Linked : the new science of networks. Cambridge, Mass: Perseus Publ., 2002.

[55] N. Marres, Digital sociology : the reinvention of social research. Malden, MA: Polity, 2017.

[56] B. Latour, Science in Action: How to Follow Scientists and Engineers Through Society. Cambridge, MA: Harvard University Press, 1987.

[57] P. Leonardi, "Theoretical foundations for the study of sociomateriality," Inf. Organ., vol. 23, no. 2, pp. 59-76, 2013. 